\title{
T Lymphocyte Cloning from Rejected Human Kidney Allografts Growth Frequency and Functional/Phenotypic Analysis
}

\author{
J. F. Moreau, M. Bonneville, M. A. Peyrat, A. Godard, Y. Jacques, C. Desgranges, “ and J. P. Soulillouł \\ Institut National de la Santé et de la Recherche Médicale, Unité U211, Faculté de Medecine, Nantes 44035 Cedex; \\ *Centre d'Epidémiologie et d'Immunovirologie, Faculté de Médecine Alexis Carrel, Lyon 69008 Cedex; \\ and $\ddagger$ Centre Hospitalier Régional de Nantes, Nantes, 44035 Cedex, France
}

\begin{abstract}
Mechanically harvested lymphocytes invading an irreversibly rejected human kidney allograft were seeded at limiting dilution to calculate the frequency of growing precursors. Opțimal growth frequency (1/13) was obtained when Epstein-Barr virus (EBV)transformed donor B lymphocytes were used as stimulators (D-BLCL) in the presence of interleukin 2 (IL-2). The 55 clones analyzed were all $\mathrm{T11}^{+}$and $\mathrm{T}^{+}$, and all expressed $\mathrm{DR}$ antigens $\left(45 \%\right.$ were $\mathrm{T}^{+}$and $\left.55 \% \mathrm{~T}^{+}\right)$. Only one clone had a doublelabeled $\left(\mathrm{T}^{+} \mathrm{T8}^{+}\right)$surface. All cells proliferated significantly against D-BLCL, although $\mathrm{T}^{+}$clones had a significantly shorter average doubling time than $\mathrm{T8}^{+}$clones. Nearly all $\mathrm{T8}^{+}$clones were specifically cytotoxic for D-BLCL, while both T4 and T8 did not react against K562, autologous EBV-BLCL, and thirdparty EBV-BLCL. Detectable IL-2 was found in the culture supernatants of only a minority of clones (all $\mathrm{T4}^{+}$).
\end{abstract}

\section{Introduction}

The histological hallmark of organ rejection is lymphocytic infiltration. These directly committed and recruited lymphocytes $(1,2)$ have been studied for years at a functional and phenotypic level in tissue or coated sponge matrix allografts $(3,4)$. In animals, transfer experiments have shown activated $\mathrm{T}$ lymphocytes to be directly involved in rejection, and purified lymphocyte subsets carrying the helper phenotype are apparently able to mediate graft destruction in immunosuppressed recipients (5). However, no definitive conclusions can be drawn in the absence of models using totally unresponsive hosts (see review [6]).

Another direct approach to the rejection mechanism is to look at the phenotypic and functional characteristics of cells within the rejected graft. The use of monoclonal antibodies $(\mathrm{MAb})^{1}$ specifically directed against surface membrane antigens has allowed precise enumeration of these lymphocytes $(7,8)$; however, all functional studies to date have been performed on crude lymphocyte suspensions extracted from rejected organs

Received for publication 21 January 1986 and in revised form 30 May 1986.

1. Abbreviations used in this paper: A-BLCL, autologous BLCL; BRMP, Biological Response Modifiers Program; BLCL, B lymphoblastoid cell line; $\mathrm{CFC}$, colony-forming cells; $\mathrm{CM}$, culture medium; D-BLCL, donor BLCL; EBV, Epstein-Barr virus; E/T, effector/target ratio; GIC, graftinvading cells; IL-1 and IL-2, interleukin 1 and 2; LU 30, lytic units, MAb, monoclonal antibody; PHA, phytohemaglutinin; rIL-2, pure recombinant IL-2.

J. Clin. Invest.

(c) The American Society for Clinical Investigation, Inc.

$0021-9738 / 86 / 10 / 0874 / 06 \quad \$ 1.00$

Volume 78, October 1986, 874-879 and have thus reflected many cell interactions. Nevertheless, there seems to be a preponderance of alloimmune cytotoxic or helper lymphocytes in human as well as in experimental animal grafts $(3,4,6,9,10)$.

The limiting dilution technique (11) can be used to clone large numbers of graft-invading cells (GIC) that can then be functionally and phenotypically characterized. Moreover, the specific frequencies of each functional or phenotypic kind of invading lymphocyte can be estimated.

This method was previously used by us $(12,13)$ to provide direct evidence for the specific involvement of several functional subsets in graft rejection. However, in these preliminary studies, the estimated lymphocyte cloning frequency was very low compared with that achieved routinely with similarly processed peripheral blood lymphocytes (PBL), a result that cast doubt on the relevance of the approach. This paper describes the characteristics of clones that were derived from a rejected human kidney. It was possible to markedly improve growth frequency by using kidney donor B lymphocytes immortilized by EpsteinBarr virus (EBV) infection as a (stimulatory) feeder layer in culture. Thus, cytotoxicity, antigen-driven proliferation, cell-surface phenotype, and interleukin 2 (IL-2) production could be determined.

\section{Methods}

(a) Clinical status of recipient. A 46-yr-old woman (HLA typing HLAA2, 3; B5, 7; DR2, W6) with end-stage renal failure caused by a chronic interstitial nephropathy received a cadaveric graft (HLA-A2, 11; B18, 22; DR5, 8) on December 28, 1983. She had been pregnant five times and had received 21 blood transfusions. Before grafting, her serum contained antibodies against 40 and $80 \%$, respectively, of $T$ and $B$ lymphocytes of a selected 20-member panel (specificity: anti-HLA A10, B12, B15, and DR7). She had no autoantibodies. Cross-match was negative with donor T lymphocytes and positive (+++) with donor B lymphocytes as determined using currently available sera. She was treated with cyclosporine as previously described (14). Her urine output remained below $1 \mathrm{liter} / 24 \mathrm{~h}$ and she required hemodialysis after transplantation. On March 3,1984 , cyclosporine was withdrawn without subsequent effect on urine output or renal function. The kidney was removed on March 27 to find symptoms of acute rejection superimposed upon the previous clinical status.

(b) EBV transformation of $B$ lymphocytes. Lymphocytes were isolated from kidney donor spleen or recipient peripheral blood by Ficoll-Hypaque density gradient centrifugation. Cells were washed twice, pelleted, and resuspended at $10^{7}$ cells $/ \mathrm{ml}$ in supernatant culture medium $(\mathrm{CM})$ of the B95.8 cell line (15) that had been filtered through a $0.45-\mu \mathrm{m}$ filter. The cells were incubated at $37^{\circ} \mathrm{C}$ and kept in suspension by regular agitation. After $2 \mathrm{~h}$, the cells were again pelleted, washed, and resuspended at $10^{6}$ cells/ml in fresh culture medium (RPMI 1640 plus $10 \%$ heat-inactivated fetal calf serum) supplemented with $0.1 \mu \mathrm{g} / \mathrm{ml}$ of cyclosporine (Sandoz, Basel, Switzerland). The cultures were then incubated at $37^{\circ} \mathrm{C}$ in a humidified atmosphere containing $5 \% \mathrm{CO}_{2}$ and fed weekly by replacement of half the supernatant. 
(c) Cell harvesting, limiting dilution assays, and clonal expansion. The procedure has been previously described in detail (11-13). Briefly, after mechanical disruption of the rejected kidney, the graft-infiltrating cells obtained were plated at densities ranging from 5 to 160 cells/well in the limiting dilution assay in the presence of $10^{3}$ irradiated $(10,000$ rad) stimulator cells. Pure recombinant IL-2 (rIL-2), kindly provided by Biogen (Geneva, Switzerland), was added to each culture at a concentration of 150 Biological Response Modifiers Program (BRMP) U/ml (see section $g$ ). The empty wells were counted after 10 to $15 \mathrm{~d}$ of culture, and the growth frequencies calculated (11). Only monoclonal cell cultures (probability $>97 \%$ ) were further expanded in IL-2-supplemented medium (150 BRMP U/ml) with occasional addition of irradiated stimulator cells (every 5-7 d).

(d) Marker analysis of colony cells. Cells were first incubated for 45 $\min$ at $4^{\circ} \mathrm{C}$ with the various murine MAb (OKT8-OKT4-OKT3-OKT11 and OKIa) diluted to 1:100. After three washes with medium (phosphatebuffered saline [PBS]-10\% human serum- $0.1 \%$ sodium azide), the cells were incubated for $30 \mathrm{~min}$ at $4^{\circ} \mathrm{C}$ with fluorescein isothiocyanate-labeled goat anti-mouse Ig (Nordic Laboratory, Tilburg, Netherlands) diluted to 1:40. They were then washed twice and resuspended in $0.025 \mathrm{ml}$ of fixative (PBS- $0.37 \%$ formaldehyde). The percentage of stained cells was then determined under an ultraviolet microscope.

(e) Cell-mediated cytotoxicity assays. A 4-h ${ }^{51} \mathrm{Cr}$-release assay (13) was used to measure the cytotoxic capacity of clones. In each experiment, at least four effector/target ratios $(\mathrm{E} / \mathrm{T})$ were tested in triplicate. The targets used were donor, autologous, and one third-party B lymphoblastoid cell line (BLCL) (HLA-A2; B12, 17; DR4, 7), and the K562 cell line. Results are expressed as percentages of specific chromium release. The spontaneous release for any target used never exceeded $15 \%$ of maximum release. Individual wells were scored positive when their counts were greater than the mean spontaneous ${ }^{51} \mathrm{Cr}$-release value of 12 wells plus three standard deviations.

(f) Proliferation assay and IL-2 production of clones. 4 or $7 \mathrm{~d}$ after the last addition of the irradiated donor B lymphoblastoid cell line (D-BLCL), cloned cells were washed three times in CM and layered over a Ficoll-Hypaque cushion to remove dead cells. After two additional washes, responding cells were counted and viable cells (>98\%) adjusted to a density of $5 \times 10^{5}$ cells $/ \mathrm{ml}$. Irradiated $(10,000 \mathrm{rad})$ BLCL stimulators (donor and autologous) were also adjusted to $5 \times 10^{5}$ cells $/ \mathrm{ml}$, and 0.1 $\mathrm{ml}$ of responding cells was added in triplicate in round-bottom wells to either $0.1 \mathrm{ml} \mathrm{CM}$ alone or to stimulator cells. $24 \mathrm{~h}$ later, $0.15 \mathrm{ml}$ of supernatant was used to measure lymphokine production. The remaining 0.05-ml cell suspension was cultured for another $24 \mathrm{~h}$. Proliferation was assessed by tritiated thymidine incorporation $(0.05 \mathrm{ml}$ of a $1: 100$ dilution of tritiated thymidine stock solution (TRK $61 ; 20-30 \mathrm{Ci} / \mathrm{mM}$ sp act, Amersham, Amersham, United Kingdom). After a 4-h pulse, cells were harvested onto fiberglass disks (Skatron, Oslo, Norway), put in $2 \mathrm{ml}$ of scintillation fluid (OCS, Amersham) and counted in a beta liquid scintillation counter.

(g) IL-2 assay. 5,000 CTLL-2 were grown in the presence of $\log _{2}$ dilutions of putative IL-2-containing medium in flat-bottomed microtiter plates (Falcon, Grenoble, France) with a total volume of $0.1 \mathrm{ml}$ in each well. $36 \mathrm{~h}$ later, $0.5 \mu \mathrm{Ci}$ of $\left[{ }^{3} \mathrm{H}\right] \mathrm{TdR}$ (TRK $61 ; 20-30 \mathrm{Ci} / \mathrm{mM}$ sp act, Amersham) was added to each well. $4 \mathrm{~h}$ later, the cells were harvested onto fiberglass disks, put in $2 \mathrm{ml}$ of scintillation fluid (OCS, Amersham) and counted in a liquid scintillation counter. IL-2 units were calculated after a previously described method (16) using a standard containing $150 \mathrm{U} / \mathrm{ml}$ of IL-2, as defined by the BRMP of the National Cancer Institute (Biological Resources Branch, Frederick Cancer Research Facility, Frederick, MD).

\section{Results}

(a) Frequency of colony-forming cells (CFC) among graft-infiltrating cells. Our preliminary experiments showing CFC frequencies obtained with a pool of 10 normal individuals' irradiated PBL as a feeder layer have been previously reported (13). This technique, limited by the shortage of available donor cells, allowed the growth of 1 out of 139 cells and 1 out of 767 cells with and without phytohemaglutinin (PHA) in the CM. The low CFC frequency as well as the subsequent slow growth rate may have been related either to the feeder cells which, for example, may not have born sufficient donor antigen, or to the use of semi-purified IL-2 obtained from PHA-stimulated PBL (17). In an effort to solve this problem, an EBV-positive D-BLCL derived from the kidney donor's splenocytes was used, after irradiation, in place of the PBL pool. Autologous B cells of recipient origin were also transformed in this way.

Fig. 1 indicates that CFC frequency from GIC could be dramatically increased by using D-BLCL as irradiated feeder in the absence of any added PHA. Under these conditions the estimated frequency was $1: 13$, whereas only $1: 2,190$ cells grew when autologous BLCL (A-BLCL) were used as feeder layer. Although recombinant (Escherichia coli), pure IL-2 was used in these and all subsequent experiments, the considerable improvement in CFC frequency was not due to the growth factor source (as indicated by control culture with rIL-2 and semipurified IL-2, data not shown) but to D-BLCL feeder cells which, as will be indicated later, provide increased alloantigen expression and may have produced IL-1 or other nonspecific growth activation factors (18). Moreover, the subsequent long-term growth rate of expanded clones was also dramatically increased, with doubling times of $\sim 24 \mathrm{~h}$ compared with $54 \mathrm{~h}$ when pooled PBL feeder was used. In several instances, a billion cells could be grown in two weeks.

(b) Colony phenotypes. In bulk GIC from four rejected kidneys studied so far, an average of $71.5 \%$ cells have been $\mathrm{T}_{1} 1^{+}$, $61 \% \mathrm{~T}^{+}$, and $14.5 \% \mathrm{~T}^{+}$(Table I). Only experiments done with GIC from kidney No. 4 (Table I) are reported in this paper, since both donor and recipient BLCL were only available in this case. The colonies obtained from this graft were grown with irradiated D-BLCL in the presence of 150 BRMP U of rIL-2 per milliliter with no lectin added. Colonies with $>97 \%$ probability of being monoclonal were studied and phenotyped at times ranging from $40 \mathrm{~d}$ to 14 mo of culture. Table II summarizes the results: $33 / 55(60.0 \%)$ of the colonies were $\mathrm{T}^{+}$, whereas $22 / 55(40.0 \%)$ were $\mathrm{T}^{+}$; these colonies were $\mathrm{T} 11^{+}$and $\mathrm{T} 3^{+}$. The

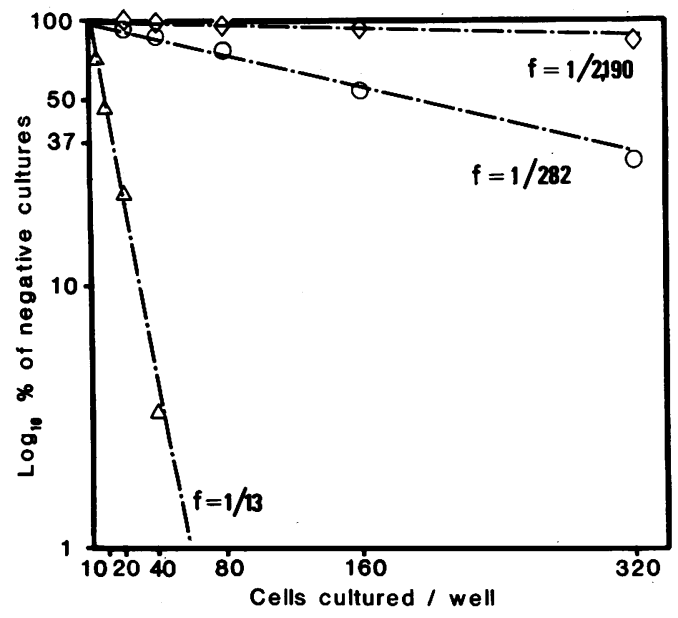

Figure 1. Limiting dilution analysis of graft-infiltrating cells. Each point represents the percent of wells in which growth was not observed for the mean number of cells per well indicated on the abscissa. Cells were cultured with $(\diamond) 1,000$ irradiated $(10,000 \mathrm{rad})$ A-BLCL per well, with (O) 1,000 pooled PBL irradiated (3,000 rad) per well, or with $(\Delta)$ 1,000 irradiated $(10,000 \mathrm{rad}) \mathrm{D}-\mathrm{BLCL}$ per well. 
Table I. Surface Marker Pattern of Graft-infiltrating Cells

\begin{tabular}{lllll}
\hline & \multicolumn{5}{l}{ Percentage of stained cells among GIC } \\
\cline { 2 - 5 } MAb tested & No. 1 & No. 2 & No. 3 & No. 4 \\
\hline OKT11 & 66 & 74 & 57 & 89 \\
OKT3 & - & - & - & 88 \\
OKT8 & 63 & 60 & 51 & 71 \\
OKT4 & 18 & 11 & 13 & 16 \\
\hline
\end{tabular}

Cells infiltrating four different kidneys were extracted and labeled with mouse MAb OKT11, OKT3, OKT8, and OKT4.

colonies were typed several times and, except for one (1F11), showed exclusive expression of T4 or T8 antigens. Although double-labeling experiments were not performed on $1 \mathrm{~F} 11,95 \%$ of the cells were $\mathrm{T}^{+}$and $40 \% \mathrm{~T}^{+}$; therefore, at least $35 \%$ were both $\mathrm{T}^{+}$and $\mathrm{T}^{+}$. This clone was included in the $\mathrm{T} 8^{+}$subgroup as most of the cells expressed T8. Class II antigen expression, as tested using the OKIA1 MAb, varied in all clones from 100 to $30 \%$ of positive cells depending on the time of testing.

(c) Cytotoxicity. All long-term cultured clones ( 55 clones to date) were tested against donor, autologous, and third-party BLCL (all these targets sharing only the HLA-A2 antigen) as well as against the K562 cell line. No clones were cytotoxic for K562. Furthermore, these clones did not kill autologous or thirdparty ${ }^{51} \mathrm{Cr}$-labeled BLCL, which emphasized that cells obtained with this system were not committed to non-donor-specific antigens such as EBV antigens. A majority were cytotoxic for D-BLCL (Table II). In these experiments, four E/T were done (0.5:1, 1:1, 5:1, and 10:1), allowing the calculation of lytic units (LU 30). However, some clones did not reach the $30 \%$ specific target lysis, although they repeatedly lysed the donor target significantly (i.e., above the threshold as calculated in Methods, section $e$ ) at the highest ratios. Therefore, in Fig. 2, the 1:1 ratio was selected because it gave the best discrimination of cytotoxic activity between clones and the same ranking as LU 30 . Some clones were highly efficient killers, with $>50 \%$ of specific ${ }^{51} \mathrm{Cr}$ release at a 1:1 E/T (Fig. 2). Almost all T8+ clones (except 1E6) were cytotoxic against D-BLCL, with 14 (out of 22) exhibiting $>20 \%$ specific ${ }^{51} \mathrm{Cr}$-release. However, only a few $\mathrm{T}^{+}$cells ( 2 out of 33) evidenced prominent ( $>20 \%$ specific ${ }^{51} \mathrm{Cr}$-release at a 1: 1 E/T) cytolytic activity, even though 14/33 clones exhibited modest cytotoxic activity (i.e., above the threshold as defined in Methods). All clones sequentially assayed have remained similarly cytotoxic for D-BLCL to the present time ( $>1 \mathrm{yr}$ in some cases).

Table II. Phenotypic and Functional Characterization of $55 \mathrm{~T}$ Cell Clones

\begin{tabular}{lll}
\hline & \multicolumn{2}{l}{ Phenotypes of clones } \\
\cline { 2 - 3 } $\begin{array}{l}\text { Cytotoxic potential } \\
\text { against D-BLCL }\end{array}$ & $\mathrm{T4}^{+}$ & $\mathrm{T}^{+}$ \\
\hline No. of positive clones & $17 / 38$ & $21 / 38$ \\
$(38 / 55)$ & $(44.74 \%)$ & $(55.26 \%)$ \\
No. of negative clones & $16 / 17$ & $1 / 17$ \\
$(17 / 55)$ & $(94.12 \%)$ & $(5.88 \%)$
\end{tabular}

(d) Proliferation and IL-2 production. All clones were tested for their proliferative responses against A-BLCL, D-BLCL, and third-party BLCL. Proliferative responses against third-party BLCL were negative (data not shown). Several differences of behavior between $\mathrm{T}^{+}$and $\mathrm{T}^{+}$clones were noted and are illustrated in Fig. 3. "Spontaneous" proliferation, as tested in medium alone, was much higher with $\mathrm{T}^{+}$than with $\mathrm{T}^{+}$clones when these cultures were tested $6 \mathrm{~d}$ after alloactivation ( $4 \mathrm{~d}$, plus $2 \mathrm{~d}$ of test), whereas $9 \mathrm{~d}$ after stimulation ( $7 \mathrm{~d}$, plus $2 \mathrm{~d}$ of test) both types of clones proliferated poorly (comparison between Fig. 3, $A$ and $B$, in medium). Secondly, proliferation in the presence of D-BLCL was also more pronounced with $\mathrm{T}^{+}$clones at day 6; however, stimulation indices were higher for $\mathrm{T}^{+}$clones due to lower "spontaneous" proliferation. Thirdly, when ABLCL were added, the resulting proliferations were significantly higher than spontaneous proliferations, indicating either that some determinants were recognized with a weak affinity or more probably that they reflected a nonspecific feeder effect from BLCL, in this particular case A-BLCL. Fourthly, the magnitude of proliferation varied with the responder/stimulator ratio. Fig. 4 illustrates this feature in a representative experiment using clone 1E7. The lower the ratio, the better the response, until a plateau is reached at a ratio of 1:6. All the above observations were made at ratios of $1: 1$. Supernatants of these cultures were screened for IL-2 bioactivity using the CTLL-2 assay. Only five $\left(\right.$ all $\mathrm{T}^{+}$) of 55 clones had released detectable IL-2 upon antigenic stimulation (Table III). Clones grown in media alone, or with A-BLCL, never elaborated IL-2. In addition, no correlation was found between IL-2 production and proliferative response.

\section{Discussion}

This paper describes a method for efficient cloning of $\mathrm{T}$ lymphocytes which invade a rejected kidney allograft and some characteristics of the clones obtained. This method can of course be applied to other tissue allografts or tumors. Our data indicate that it is now possible to obtain cytotoxic or helper clones in large numbers and also provide further information on phenotypes, functions, and phenotype/function relationships of GIC in a direct approach to the immunological events leading to allograft rejection.

As compared with previous attempts to clone GIC using a pool of normal PBL as feeder layer (13), use of EBV-transformed BLCL derived from the graft donor dramatically improved the frequency of IL-2-dependent CFC (i.e. from 1:767 to 1:13). The improved cloning efficiency may be due to one or more nonspecific factors produced by EBV-transformed BLCL, such as IL-1 (18-20).

Although such nonspecific factors may have contributed to the high CFC frequency observed, they appear to be effective only in conjunction with antigen, since autologous feeder yielded only a 1:2,190 colony frequency. Furthermore, the availability of D-BLCL allows indefinite use of specific donor antigens instead of third-party cells bearing certain shared HLA antigens. This antigen presentation was of major importance in our study, since A-BLCL yielded a very low frequency of CFC $(1: 2,190)$, indicating that nearly all tested colonies were alloresponsive and not responsive against EBV-encoded surface determinants presented by self-major histocompatibility complex molecules.

Apart from their efficiency in the limiting dilution phase of cloning, immortilized D-BLCL were also required in large 
T4

\% specific ${ }^{51} \mathrm{Cr}$ release

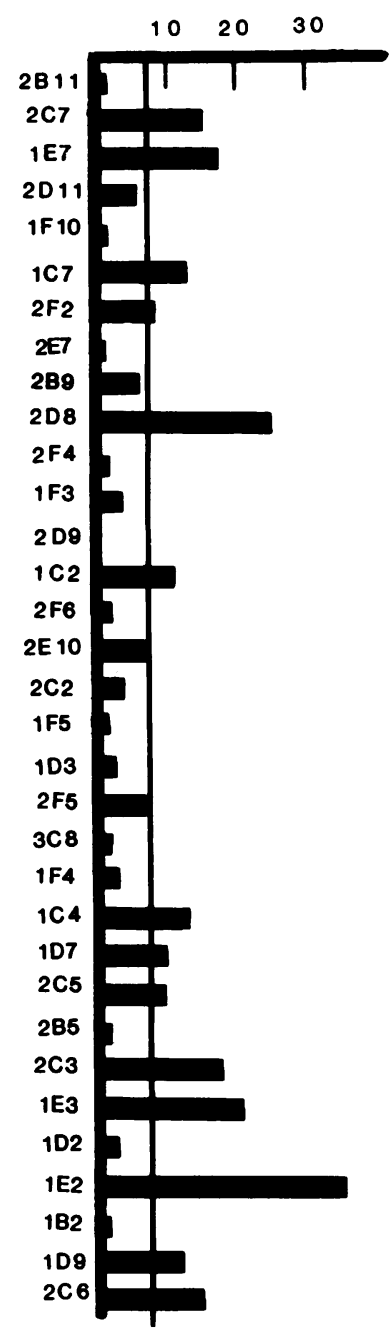

T8

\% specific ${ }^{51} \mathrm{Cr}$ release

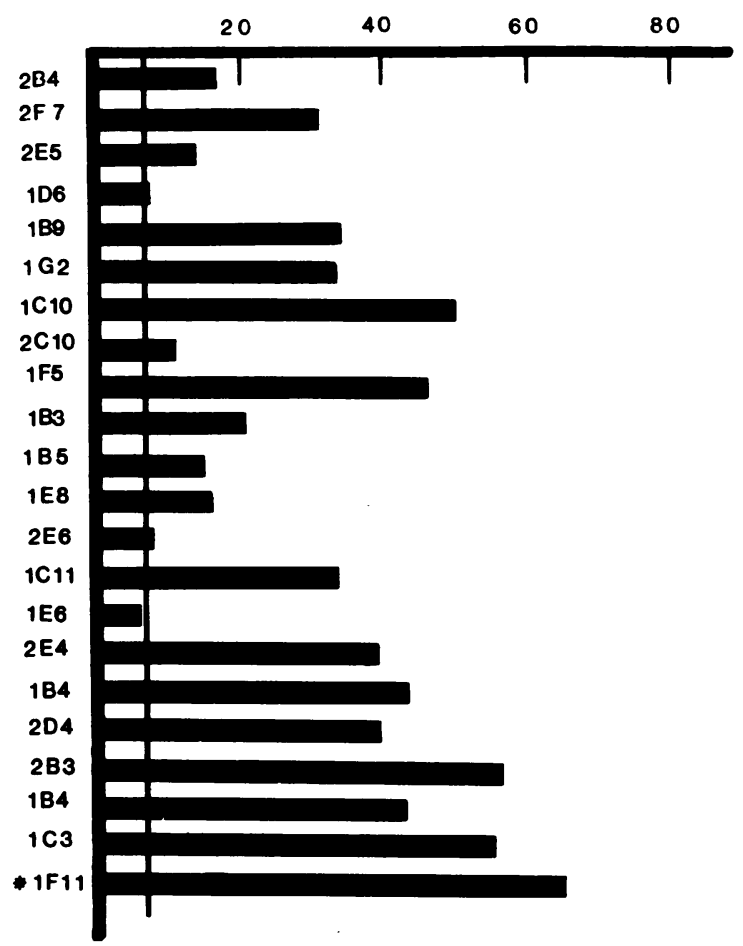

Figure 2. Cytotoxic potential of $33 \mathrm{~T}^{+}$ clones and of $22 \mathrm{~T}^{+}$clones. Each bar indicates the percentage of specific ${ }^{51} \mathrm{Cr}$-release observed on the D-BLCL as target at an E/T of 1:1 (see Results, section $c$ ). Clone $1 \mathrm{~F} 11(*)$ was a mixture of $\mathrm{T}^{+}, \mathrm{T}^{+}$, and $\mathrm{T}^{+}{ }^{+} \mathrm{T}^{+}$cells (see Methods). The vertical line represents the cutoff for positives and negatives as defined in Methods (section $e$ ). quantities to obtain similarly large numbers (greater than one billion alloreactive clonal cells within 2 wk of culture in several instances) of clonally derived cells needed for functional or molecular characterization of the derived clones.

The identified phenotypes of the cloned cells were somewhat curious, since $\mathrm{T}^{+}$clones were more numerous than $\mathrm{T}^{+}$clones, whereas our previous studies $(12,13)$ and others $(21,22)$ have indicated that the reverse profile is commonly observed within rejected kidneys assessed either in tissue sections or from fine needle aspiration biopsies. Indeed, the starting GIC bulk material used in these experiments also contained a majority of $\mathrm{T}^{+}$cells (71\%). As $\mathrm{T}^{+}$clones had a consistently lower doubling time than $\mathrm{T}^{+}$in similar in vitro culture conditions, it may be supposed that the rejected kidney microenvironment provides one or more factors (lacking in the culture vessel) that enhance $\mathrm{T}^{+}$ cell growth locally or trap $\mathrm{T}^{+}$cells in grafts. These factors may be produced by regulatory cells such as $\mathrm{T}^{+}$lymphocytes and would thus be absent from the clonal culture system and distinct from IL-2. Alternatively, a higher proportion of $\mathrm{T}^{+}$GIC than $\mathrm{T}^{+}$cells may not be specifically committed to the donor antigens and hence fail to grow when challenged with D-BLCL. Exper- iments using $\mathrm{T}^{+}$clone culture supernatants in $\mathrm{T} 8^{+}$cultures (in the presence of rIL-2) to detect eventual growth-enhancing factor(s) produced by $\mathrm{T}^{+}$cultures are in progress. Only a few clones produced detectable amounts of IL-2 when stimulated by DBLCL, although they were strongly induced to proliferate in the absence of exogenous rIL-2 by the stimulator cells. The most likely explanation that would fit with the accepted model of antigen-driven lymphocyte growth involving autocrine production/consumption of IL-2 (23) is that the IL-2 produced by the clone is immediately bound to the receptors that appear at extremely high density. Only quantitative study of related messenger RNA (mRNA)-IL-2 production after D-BLCL challenge will, however, provide definitive evidence for this hypothesis.

As alloreactive $\mathrm{T}^{+}$and $\mathrm{T}^{+}$cells are likely effectors involved in class I and class II recognition, respectively (24), the high cytotoxicity score of $\mathrm{T}^{+}$clones suggests a major role for this lymphocyte subset in the rejection process; however, their role may be dependent on the helper effect of the neighboring $\mathrm{T}^{+}$. No clones displaying cytotoxicity to K562 were found. That $\mathrm{K} 562$, in addition to being a natural killer-sensitive target, is lysed by lymphokine-activated killers reinforces the finding that 

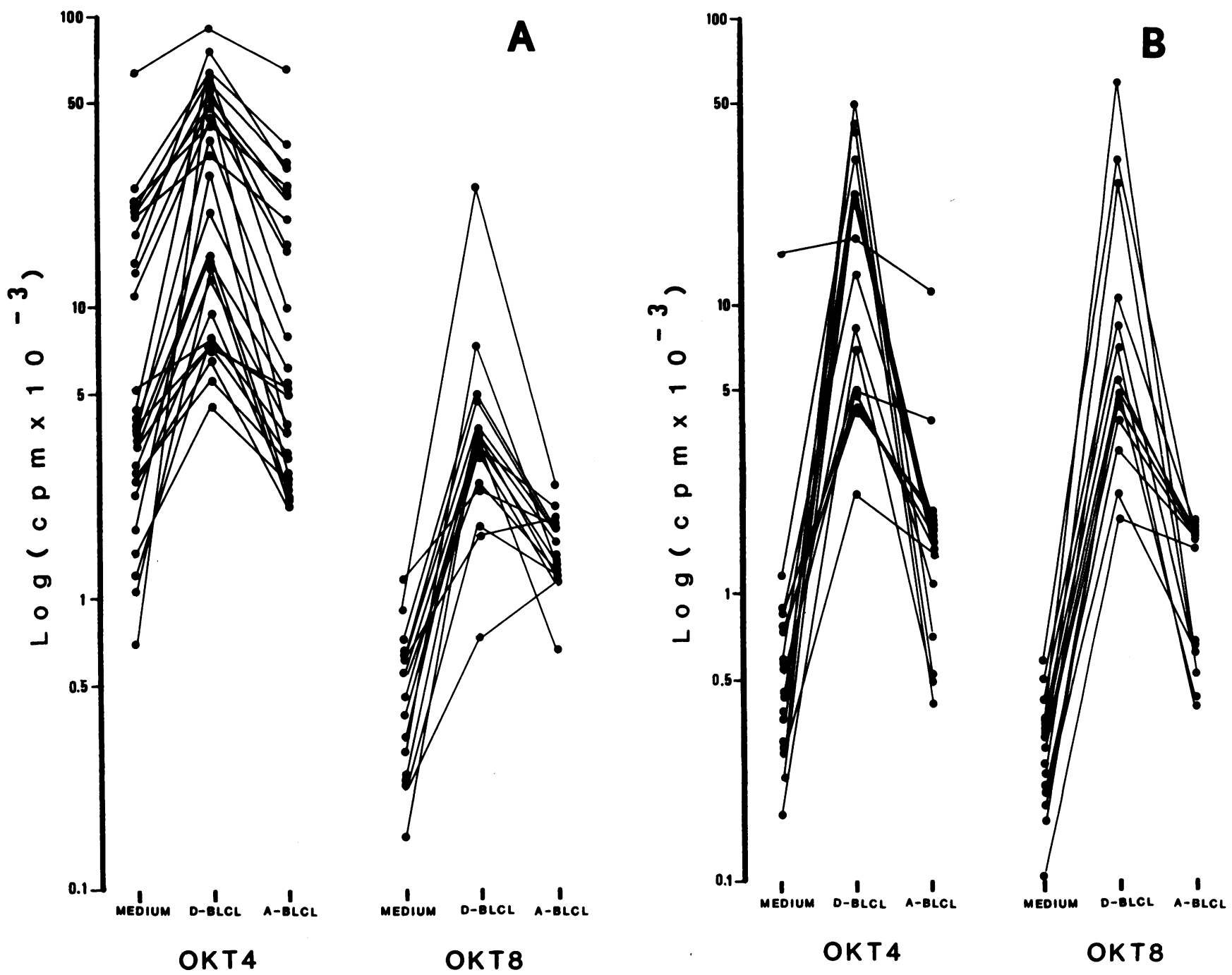

Figure 3. Proliferation response of clones $6 \mathrm{~d}(A)$ and $9 \mathrm{~d}(B)$ after the last stimulation by the D-BLCL. $\left[{ }^{3} \mathrm{H}\right] \mathrm{TdR}$ incorporation of T4 and T8 ${ }^{+}$ clones was assayed in medium alone, in presence of irradiated (10,000 rad) D-BLCL, and in presence of irradiated (10,000 rad) A-BLCL, at a responder/stimulator ratio of $1: 1$.

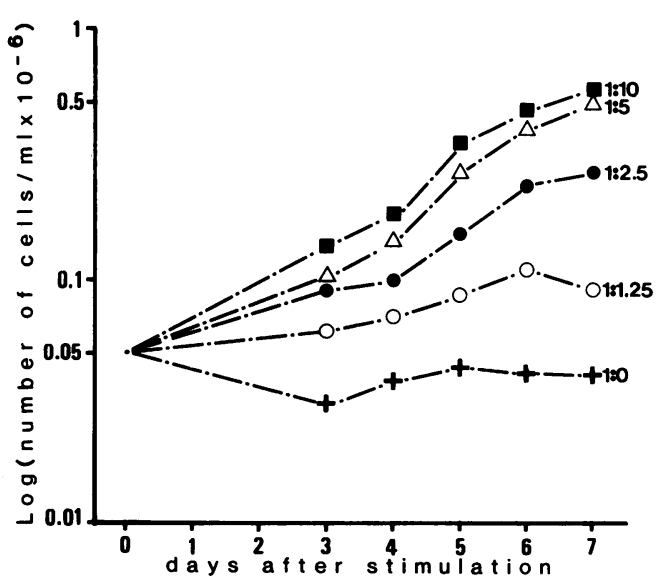

Figure 4. Effect of the responder/stimulator ratio on the growth of one clone (1E7). Identical numbers of $1 E 7$ cells $\left(5 \times 10^{5}\right)$ were seeded without (1:0) or with increasing numbers of irradiated $(10,000 \mathrm{rad})$ D-BLCL $(1: 1.25,1: 2.5,1: 5$, and 1:10) at the initiation of the cultures (day zero). Cell counts, expressed on the ordinate, were followed from day 3 to day 7 . the clones obtained were all alloreactive. Nevertheless, the following question arises: what is the nature of the remaining lymphocytes $(90 \%)$ that do not grow in this system? A possible explanation would be that the experimental system is still unable

Table III. IL-2 Titers of the Five Secreting Clones

\begin{tabular}{llll}
\hline & \multicolumn{2}{l}{ Culture conditions } & \\
\cline { 2 - 3 } Clones & Medium & D-BLCL & A-BLCL \\
\hline 2C6 & 0 & 50 & 0 \\
2B9 & 0 & 16.5 & 0 \\
2D8 & 0 & 5.25 & 0 \\
1C4 & 0 & 2.21 & 0 \\
2F4 & 0 & 3.90 & 0
\end{tabular}

II-2 activities in supernatants from clones either nonstimulated (medium) or stimulated with D-BLCL and with A-BLCL were assayed on CTLL-2 and expressed in BRMP units per milliliter in the Methods section. 
to recruit satisfactorily all the committed cells against donor antigens.

However, with the same culture system (11), two-thirds of the PBL from normal individuals in the presence of PHA and with autologous cells as feeder cells are able to grow, which suggests that the culture conditions are not limiting. It is also possible that the nongrowing cells may be committed against antigens absent from the surface of D-BLCL. Such antigens present on kidney cells, whether restricted by major histocompatibility complex antigens or not, have been described as targets in allorejections (25-27). Conversely, these unresponsive lymphocytes are not, perhaps, actually committed against graft antigens, but are recruited by other committed cells that produce chemotactic factors within the rejected graft. Finally, it must be emphasized that our data applied to a case of definitive graft rejection in a recipient who was without an immunosuppressive regimen for weeks. The GIC frequency and the functional patterns obtained may be somewhat different in other types of rejection. Nevertheless, cellular infiltrates collected by the mean of the fine needle aspiration biopsy may be used by the method we herein described for the analysis of rejection. Different types of rejection and their evolution could thus be studied.

\section{Acknowledgments}

We thank Biogen (Geneva, Switzerland) for supplying recombinant IL-2, Mrs. A. Bertho for her technical assistance, and Dr. J. Gray for reviewing the manuscript.

\section{References}

1. Platt, J. L., T. W. Lebien, and A. F. Michael. 1982. Interstitial mononuclear cell populations in renal graft rejection: identification by monoclonal antibodies in tissue sections. J. Exp. Med. 155:17-30.

2. Ascher, N. L., S. Chen, R. Hoffman, and R. Simmons. 1983. Maturation of cytotoxic $\mathrm{T}$ cells within sponge matrix allografts. J. Immunol. 131:617-621.

3. Strom, T. B., N. L. Tilney, C. B. Carpenter, and G. J. Busch. 1975. Identity and cytotoxic capacity of cells infiltrating renal allografts. N. Engl. J. Med. 292:1257-1263.

4. Strom, T. B., N. L. Tilney, J. M. Paradysz, J. Bancewicz, and C. B. Carpenter. 1977. Cellular components of allograft rejection: identity, specificity and cytotoxic function of cells infiltrating acutely rejecting allografts. J. Immunol. 118:2020-2026.

5. Loveland, B. E., P. M. Hogarth, R. Ceredig, and I. F. C. McKenzie. 1981. Cells mediating graft rejection in the mouse. I. Lyt-1 cells mediate skin graft rejection. J. Exp. Med. 153:1044-1057.

6. Steinmuller, D. 1985. Which T cells mediate allograft rejection? Transplantation (Balt.). 40:229-233.

7. Hancock, W. W., N. M. Thomson, and R. C. Atkins. 1983. Composition of interstitial cellular infiltrate identified by monoclonal antibodies in renal biopsies of rejecting human renal allografts. Transplantation (Balt.). 35:458-462.

8. Häyry, P., and E. Von Willebrand. 1984. Transplant aspiration cytology. Transplantation (Balt.). 38:7-12.

9. Ascher, N. L., R. Hoffman, D. W. Hants, and R. L. Simmons. 1983. Cellular events within the rejecting allograft. Transplantation (Balt.). 35:193-197.

10. Mayer, T. G., A. A. Fuller, T. C. Fuller, A. I. Lazarovits, L. A. Boyle, and J. T. Kurnick. 1985. Characterization of in vivo-activated allospecific T lymphocytes propagated from human renal allograft biopsies undergoing rejection. J. Immunol. 134:258-264.

11. Moreau, J. F., and R. G. Miller. 1983. Growth at limiting dilution of human $\mathrm{T}$ cell colonies from $\mathrm{T}$ cell depleted peripheral blood leukocytes. J. Immunol. 130:1139-1145.

12. Moreau, J. F., H. Vie, M. A. Peyrat, and J. P. Soulillou. 1985. Function and cell surface markers of cloned T lymphocytes obtained from rejected human kidney allografts. Transplant. Proc. 17:810-815.

13. Moreau, J. F., M. A. Peyrat, H. Vie, M. Bonneville, and J. P. Soulillou. 1985. T cell colony-forming frequency of mononucleated cells extracted from rejected human kidney transplants. Transplantation (Balt.). 39:649-656.

14. Hourmant, M., J. P. Soulillou, and J. Guenel. 1985. Comparison of three immuno-suppressive regimens in kidney transplantation. Transplant. Proc. 17:1158-1161.

15. Miller, G., T. Shope, H. Lisco, D. Stitt, and M. Lipman. 1972. Epstein-Barr virus: transformation cytopathic changes and viral antigens in squirrel monkey and marmouset leucocytes. Proc. Natl. Acad. Sci. USA. 69:383-387.

16. Bertoglio, J., N. Boisson, M. C. Bonnet, et al. 1982. First French Workshop on standardization of human IL2: joint report. Lymphokine Res. 1:121-125.

17. Godard, A., J. Naulet, M. A. Peyrat, H. Vie, J. F. Moreau, and J. P. Soulillou. 1984. Preparative double step purification of human IL2 using high performance liquid chromatography and hydrophobic affinity. J. Immunol. Methods. 70:233-244.

18. Arnold, A., S. Lipkowitz, M. Suthanthiran, A. Novogrodski, and K. H. Stenzel. 1985. Human B lymphoblastoid cell lines provide an ILllike signal for mitogen treated T lymphocytes via direct cell contact. $J$. Immunol. 134:3876-3881.

19. Van de Griend, R. J., B. A. Van Krimpen, S. J. L. Bol, A. Thompon, and R. L. H. Bolhuis. 1984. Rapid expansion of human cytotoxic $T$ cell clones: growth promotion by a heat labile serum component and by various types of feeder cells. J. Immunol. Methods. 66:285-298.

20. Van de Griend, R. J., and R. L. H. Bolhuis. 1984. Rapid expansion of allospecific cytotoxic $T$ cell clones using non-specific feeder cell lines without further addition of exogenous IL2. Transplantation (Balt.). 38: 401-406.

21. Von Willebrand, E. 1983. OKT4/8 ratio in the blood and in graft during episodes of human allograft rejection. Cell. Immunol. 77: 196-201.

22. Tufveson, G., U. Forsum, K. Claesson, L. Klareskog, E. Larsson, A. Karlsson-Parra, and L. Frödin. 1983. T lymphocyte subsets and HLADR expressing cells in rejected human kidney grafts. Scand. J. Immunol. 18:37-40.

23. Meuer, S. C., R. E. Hussey, D. A. Cantrell, J. C. Hodgdon, S. F. Schlossman, K. A. Smith, and E. L. Reinherz. 1984. Triggering of the T3-Ti antigen-receptor complex results in clonal T-cell proliferation through an IL2-dependent autocrine pathway. Proc. Nat'l Acad. Sci. USA. 81:1509-1513.

24. Meuer, S. C., J. C. Hodgdon, D. A. Copper, R. E. Hussey, K. A. Fitzgerald, S. F. Schlossman, and E. L. Reinherz. 1983. Human cytotoxic $T$ cell clones directed at autologous virus-transormed targets: further evidence for linkage of genetic restriction to T4 and T8 surface glycoproteins. J. Immunol. 131:186-190.

25. Wilson, C. B., D. H. Lehman, R. C. McCoy, J. C. Gunnells, and D. C. Stickel. 1975. Antitubular basement membrane antibodies after renal transplantation. Transplantation (Balt.). 18:447-452.

26. Manca, F., S. Barocci, A. Kunkl, G. Gurreri, M. Costantini, and F. Celada. 1983. Recognition of donor fibroblast antigens by lymphocytes homing in the human grafted kidney. Transplantation (Balt.). 36:670674.

27. Roth, D., L. Fuller, V. Esquenazi, K. Kyriakides, V. Pardo, and J. Miller. 1985. The biologic significance of the mixed lymphocyte kidney culture in humans. Transplantation (Balt.). 40:376-383. 